University of Wollongong

Research Online

Faculty of Engineering and Information

Faculty of Engineering and Information

Sciences - Papers: Part A

Sciences

January 2014

\title{
Fabrication of nanostructured aluminum sheets using four-layer accumulative roll bonding
}

Hailiang Yu

University of Wollongong, hailiang@uow.edu.au

Cheng Lu

University of Wollongong, chenglu@uow.edu.au

A Kiet Tieu

University of Wollongong, ktieu@uow.edu.au

Charlie Kong

University of New South Wales

Follow this and additional works at: https://ro.uow.edu.au/eispapers

Research Online is the open access institutional repository for the University of Wollongong. For further information contact the UOW Library: research-pubs@uow.edu.au 


\title{
Fabrication of nanostructured aluminum sheets using four-layer accumulative roll bonding
}

\begin{abstract}
In this paper, an extended accumulative roll bonding (ARB) technique, called the 'Four-Layer Accumulative Roll Bonding (FL-ARB)' technique, is presented for the first time. This technique has been employed to produce ultrafine-grained commercial pure aluminum sheets with success. After three FL-ARB passes, the grain size of pure aluminum was seen to reduce to $380 \mathrm{~nm}$. The bonding strength of the sheets after rolling has also been discussed. Theoretical calculations showed that the bonding strength of sheets processed by the FL-ARB technique can be 2-2.2 times greater than that by the traditional ARB technique. The main advantages of the FL-ARB technique are (a) improvement of the interface bonding, with increasing deformation in each pass, (b) applicability of the technique at room temperature to process most metals, and (c) generation of the largest equivalent strain in the workpiece with the same number of passes, compared with other severe plastic deformation techniques.
\end{abstract}

\section{Keywords}

roll, bonding, fabrication, nanostructured, aluminum, sheets, four, layer, accumulative

\section{Publication Details}

Yu, H. Y., Lu, C., Tieu, A. K. \& Kong, C. (2014). Fabrication of nanostructured aluminum sheets using fourlayer accumulative roll bonding. Materials and Manufacturing Processes, 29 (4), 448-453. 


\title{
ACCEPTED MANUSCRIPT
}

\section{Fabrication of Nanostructured Aluminum Sheets Using Four-Layer Accumulative Roll Bonding}

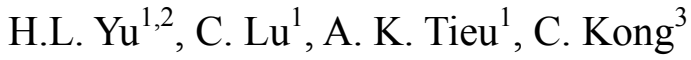 \\ ${ }^{1}$ School of Mechanical, Materials \& Mechatronics Engineering, University of \\ Wollongong, NSW, Australia ${ }^{2}$ School of Mechanical Engineering, Shenyang University, \\ Shenyang, China, ${ }^{3}$ Electron Microscope Unit, University of New South Wales, Sydney, \\ NSW, Australia
}

Address correspondence to H.L. YU, School of Mechanical, Materials \& Mechatronics Engineering, University of Wollongong, NSW 2500, Australia; E-mail: yuhailiang1980@tom.com or hailiang@uow.edu.au

Received July 4, 2013; Accepted November 25, 2013

\begin{abstract}
In this paper, an extended Accumulative Roll Bonding (ARB) technique, called the 'Four-Layer Accumulative Roll Bonding (FL-ARB)' technique, is presented for the first time. This technique has been employed to produce ultrafine-grained commercial pure aluminum sheets with success. After three FL-ARB passes, the grain size of pure aluminum was seen to reduce to $380 \mathrm{~nm}$. The bonding strength of the sheets after rolling has also been discussed. Theoretical calculations showed that the bonding strength of sheets processed by the FL-ARB technique can be $2 \sim 2.2$ times greater than that by the traditional ARB technique. The main advantages of the FL-ARB technique are (a) improvement of the interface bonding, with increasing deformation in each pass, (b)
\end{abstract}




\section{ACCEPTED MANUSCRIPT}

applicability of the technique at room temperature to process most metals (c) generation of the largest equivalent strain in the workpiece with the same number of passes, compared with other severe plastic deformation techniques.

KEYWORDS: Aluminum; Bonding; Deformation; Experimentation; Formation; Manufacturing; Metalforming; Processes; Rolling

\section{INTRODUCTION}

Ultrafine-grained materials (grain size ranging from $100 \mathrm{~nm}$ to $1000 \mathrm{~nm}$ ) have a lot of desirable properties: (i) high strength at room temperatures (Hall-Petch relationship); (ii) high corrosion resistance (Relationship between hardness and strength); (iii) high-speed super-plastic deformation at elevated temperatures (reduction of stress concentration due to reduced grain size). Such materials have attracted increasing attention in the past twenty years [1].

A number of Severe Plastic Deformation (SPD) techniques have been employed to fabricate nanostructured / ultrafine-grained bulk materials. These techniques include: Equal-Channel Angular Press / Extrusion (ECAP/ECAE) [2, 3], High Pressure Torsion (HPT) [4, 5], Groove Pressing (GP) [6-8], Twist Extrusion (TE) [9], Asymmetric Rolling 


\section{ACCEPTED MANUSCRIPT}

(AR) $[10,11]$, Accumulative Roll Bonding (ARB) [1, 12-14], and Accumulative Back Extrusion (ABE) [15]. The ECAP technique was employed to produce ultrafine grained AA1070 and AA6060 samples by Hockauf and Meyer [2]. They found that the pinning effect of the sheared precipitates have a great influence on refinement of the grain size of the materials. Ito and Horita [4] studied the evolution of the microstructure in pure aluminum by HPT. The grain refinement was seen to occur in the following sequence: dislocation accumulation, subgrain boundaries formation, misorientation angle enhancement, and high-angle boundary formation, before finally attaining a steady state. Sajadi et al. [6] produced aluminum samples with uniform mechanical properties by the Constrained Groove Pressing (CGP) technique. The main drawbacks of the ECAP, HPT, $\mathrm{TE}$ and CGP techniques are: (i) the productivity is relatively very limited; (ii) the techniques are only suitable for small samples; (iii) expensive and large load capacity dies are required. Compared to the above techniques, the ARB technique has the ability to produce continuous ultrafine grained sheets in large quantities. Saito et al [12] used the ARB technique to produce AA1100 samples with ultrafine grains (grain size about 670 nm) after 6 passes. After ten ARB cycles on AA1100, Pirgazi et al [13] found the grain size to be about $500 \mathrm{~nm}$. However, the ARB technique also has a weakness: as the reduction ratio in each pass is set to $50 \%$, the bonding quality between the two layers is difficult to control and it is difficult to manufacture the product from most metallic materials at ambient temperature. A good quality of interface bonding during cold rolling of most metals requires a reduction ratio of more than 70\%, as shown in Fig. 1 [16]. 


\section{ACCEPTED MANUSCRIPT}

In this paper, we present for the first time a newly developed 'Four-Layer Accumulative

Roll Bonding' (FL-ARB) technique. The FL-ARB technique has been successfully used to produce ultrafine-grained pure aluminum sheets. Compared with the traditional ARB technique, the FL-ARB technique has a greater ability to produce ultrafine-grained sheets at room temperature with a good interface bonding strength.

\section{EXPERIMENTAL INVESTIGATION}

Fig. 2 is a schematic illustration of the FL-ARB technique. In the FL-ARB process, a sheet is cut into four samples of equal size, and then the four samples are neatly stacked. The interfaces between the any two adjacent sheets are surface-treated in advance for improvement of the bond strength. With a $75 \%$ reduction ratio, the four layers are bonded together through a conventional roll bonding process. The rolled product is cut into four parts lengthwise. The pieces are repeatedly surface-treated, stacked and roll-bonded. The whole process is repeated a number of times. Compared with the traditional ARB technique, the main advantages of the FL-ARB technique are: (a) an improvement of the interface bonding with a higher rolling reduction ratio in each pass, and (b) potential application at room temperature.

The FL-ARB technique was used to produce ultrafine-grained pure aluminum sheets. Commercial Aluminum 1235 alloy sheets having $0.3 \mathrm{~mm}$ thickness were used. The 


\section{ACCEPTED MANUSCRIPT}

chemical composition of the material is listed in Table 1 . The sheets were annealed to achieve a fully homogeneous microstructure. The FL-ARB process was carried out using a multi-function rolling mill having a $120 \mathrm{~mm}$ diameter roll and a maximum rolling force of $50 \mathrm{kN}$. Initially, the four sheets were stacked together and welded at one end. The composite sheet was rolled with a nominal reduction of $75 \%$ under dry conditions for each FL-ARB pass. The resulting $0.3 \mathrm{~mm}$ thick sheets were then cut into four parts, and repeatedly subjected to the second and third rolling passes. The micro-hardness of the samples was tested after each pass. In addition, after each FL-ARB pass, an FEI xT Nova Nanolab 200 Dual-beam workstation was used to prepare thin-foil specimens from the samples for further TEM observation. The specimens were placed on a standard carbon film $\mathrm{Cu}$ grid using an ex-situ lift-out method. A Philips CM200 Field Emission Gun Transmission Electron Microscope (FEG/TEM) equipped with a Bruker Energy Dispersive X-ray (EDAX) Spectroscopy system operating at an accelerating voltage of $200 \mathrm{kV}$ was used to investigate the details of the microstructure.

\section{RESULTS AND DISCUSSION}

\section{Microstructure And Mechanical Properties}

Fig. 3 shows the TEM images and Vickers micro-hardness of the FL-ARB processed samples. Figures 3(a) to 3(c) are the TEM images of the FL-ARB-processed samples 


\section{ACCEPTED MANUSCRIPT}

after the first, second and third pass respectively. As the number of rolling passes increases, the grain size of the samples gradually decreases. After the first pass, the average grain size was about $700 \mathrm{~nm}$; after the second pass, the average grain size reduced to $520 \mathrm{~nm}$. After the third pass, the average grain size of the sample decreased to $380 \mathrm{~nm}$. In the SPD process, the grain size gradually decreases with increasing equivalent strain. Kavarana et al. [17] produced multilayer brass/steel laminates with the bilayer thickness between $39.2 \mathrm{~nm}$ and $78.4 \mathrm{~nm}$ with reduction ratio up to $99.97 \%$ by cold rolling of stacked sheets. However, a number of studies have shown that in ARB processing, the grain size does not continue to decrease after the sixth pass $[12,14]$. In the present study, the mean thickness of layers after the third pass was seen to be $4.6 \mu \mathrm{m}$ after three FL-ARB passes. Figure 3(d) shows the micro-hardness as a function of the number of FL-ARB passes. As seen in Figure 3(d), after the first FL-ARB pass, the micro-hardness increases from $43 \mathrm{HV}$ to $55 \mathrm{HV}$. However, with further passes, the micro-hardness of the samples reduces again. This phenomenon has also been observed in many studies on pure aluminum subjected to SPD processes [18, 19]. Edalati and Horita [19] gave a detailed discussion about the 'stacking fault energy' which affects the dislocation mobility and the dynamic softening that occurs more quickly to reach a steady state in Al-rich materials. However, the eventual grain size (in the steady state) is independent of the stacking fault energy [19]. 


\section{ACCEPTED MANUSCRIPT}

Fig. 4 shows the average grain size of pure aluminum samples attained with different SPD techniques. With the ECAP technique, the average grain size of the pure aluminum reaches $660 \mathrm{~nm}$, with the equivalent strain reaching 9.2 [2]. Using the ARB technique, Saito [12] and Pirgazi et al. [13] developed ultrafine-grained bulk pure aluminum with an average grain size of $670 \mathrm{~nm}$ and $500 \mathrm{~nm}$ after six and ten passes respectively. When using the GP technique, the grain size was reduced to $1000 \mathrm{~nm}$ after four passes for commercially pure aluminum [8]. With a semi-constrained GP process, Morattab et al. [7] obtained an average grain size of $300 \mathrm{~nm}$ in pure aluminum after four passes. When using the TE technique, the average grain size was reduced to about $1600 \mathrm{~nm}$ at the outer edge after 4 passes [9]. When using the HPT technique, the grain size at the sample edge is about 100-200 nm, while at the sample center it is $600 \mathrm{~nm}$ for Al 1050 when the equivalent strain is in the range $4.2 \sim 5.8$. Zuo et al. [11] observed extremely fine $500 \mathrm{~nm}$ grains in pure aluminum at room temperature using the AR technique. Yu et al. [10] obtained samples with grain size in the range $211 \mathrm{~nm} \sim 360 \mathrm{~nm}$ at cryogenic temperatures. When using the FL-ARB technique, the average grain size was seen to be $380 \mathrm{~nm}$. With the exception of the TE technique, all the other techniques mentioned above can produce ultrafine-grained samples with a grain size less than $1000 \mathrm{~nm}$.

Table 2 shows the equivalent strain per pass for various SPD techniques. The equivalent strain increases to 0.56 after one pass of GP processing, and to 0.8 for the ARB and HPT techniques. It increases to 1.0 and 1.2 for ECAP and TE, and 1.6 for FL-ARB. It is 


\section{ACCEPTED MANUSCRIPT}

obvious that the FL-ARB can induce the largest strain in the samples. This implies that the process requires a smaller number of passes to obtain the same total equivalent strain in the workpiece. The FL-ARB is thus seen to be a technique that could be used to produce metallic nanostructured materials.

\section{Bond Strength Of Interface}

The rolling employed in the ARB is not only a deformation process, but also a bonding process. The bonding quality of the interface is not only affected by the surface treatment, but also by the processing temperature and the deformation ratio. As the reduction ratio is set to $50 \%$ in traditional $\mathrm{ARB}$ processing, the rolling temperature has to be raised to improve the bonding quality. Fig. 5 shows samples produced by the traditional ARB process (a) at room temperature and (b) at $200^{\circ} \mathrm{C}$. When the rolling is carried out at room temperature, there is no bonding at the interface between the two layers. When the samples were rolled at $200^{\circ} \mathrm{C}$, there are still some residual voids around the interface [22]. In Fig. 3 (a) - Fig. 3 (c), it is seen that there are no residual voids in the interface zone, which implies that a good quality of interfacial bonding for the aluminum alloys could be obtained through the FL-ARB technique at room temperature. Yu et al. [23] studied the interface bonding quality under different heating temperatures, reduction ratios, etc. At higher temperature, the atoms on the interface surfaces can migrate more easily, corresponding to a higher diffusion coefficient. This improves the bond quality, as shown 


\section{ACCEPTED MANUSCRIPT}

in Fig. 5 (b). With greater reduction ratio, the deformation of the protrusions on the interfaces increases, increasing the contact surface. For a given deformation temperature, the driving force for the diffusion is unchanged. With increasing deformation, the stress gradient increases, so that the driving force for atomic diffusion at the interfaces increases. This accelerates the formation of bonds across the interfaces, as shown in Fig. 3(a) - (c).

In the present study, the FL-ARB process is carried out at room temperature. As shown in Fig. 1, the bonding strength is related to the reduction ratio during cold roll bonding. For most metals, the rolling reduction ratio should be greater than $70 \%$. Fig. 6 shows the relationship between the reduction ratio and the number of stacked sheets in each pass. When the number of stacked sheets is 2 , the reduction ratio is $50 \%$, the bonding quality will be very weak, as shown in Fig. 5 (a). When the number of stacked sheets is 3 , the reduction ratio increases to $66.6 \%$ which is still less than $70 \%$. When the number of stacked sheets is 4 and 5, the reduction ratios increase to $75 \%$ and $80 \%$ respectively. Under these rolling conditions, the rolled sheets will have high bonding quality according to the relationship between bonding quality and reduction ratio in Fig. 1. Thus, the number of stacked layers should be 4 or more, if a good bonding quality is the only consideration. However, with increasing reduction ratio, the rolling force, rolling torsion, roll wear, etc. will increase greatly, which will greatly increase the losses in the roll mill. Thus, here we suggest that the optimum number of stacked layers is 4 . 


\section{ACCEPTED MANUSCRIPT}

Eqs. (1) [24], and (2) [25] have been proposed to determine the bonding strength of the interface during rolling:

$$
\begin{aligned}
& \sigma_{b}=\left(\frac{\sqrt{3}}{2}\right)^{n} \frac{\sigma_{0}}{K} \ln \left(\frac{1}{1-R_{f}}\right) \\
& \sigma_{b}=K_{1} \sigma_{0} \exp \left(-\frac{\sqrt{3}}{2} K_{2} \varepsilon_{e}\right)
\end{aligned}
$$

where $\sigma_{\mathrm{b}}$ is the bond strength, $\sigma_{0}$ the tensile stress of sheets, $R_{f}$ the final reduction ratio; $\varepsilon_{\mathrm{e}}$ the equivalent strain in the strips; $n, K, K_{1}$ and $K_{2}$ are plasticity constants depending on the sheet material and the preparation process of the welded surfaces. Equations (1) and (2) suggest that the bonding strength at the interface of multilayer metallic materials achieved by rolling is related to the reduction ratio and the equivalent strain at the interfaces. It is seen in Table 2 that the reduction ratios in the strip are $50 \%$ for ARB and $75 \%$ for FL-ARB, and the equivalent strains in the strip are 0.8 for ARB and 1.6 for FL-ARB. Using Equations (1) and (2), it is possible to evaluate the bonding strength of interface by FL-ARB and traditional ARB techniques. Using Equation (1), the bonding strength of interface by FL-ARB is seen to be 2 times of that by ARB process with the same materials. In addition, Equation (2) gives the bonding strength of the interface by FL-ARB as 2.2 times of that achieved by traditional ARB. The FL-ARB can thus be proposed as an advanced manufacturing technique that can be used to produce long and continuous ultrafine-grained sheets at room temperature. In addition, because FL-ARB does not require the samples to be pre-heated, it is a more energy-efficient technique compared to the traditional ARB technique. 


\section{ACCEPTED MANUSCRIPT}

\section{CONCLUSIONS}

For the first time, a new method called the 'Four-Layer Accumulative Roll Bonding (FL-ARB)' technique, has been used successfully to fabricate ultrafine-grained pure aluminum with average grain size $380 \mathrm{~nm}$ after three passes. For each FL-ARB rolling pass, the material was subjected to a reduction ratio of $75 \%$.

Compared with the traditional ARB technique, the main advantages of the FL-ARB technique are: (a) improvement of the interface bonding by more than $200 \%$, with a high equivalent strain of 1.6 in each FL-ARB pass, and (b) possibility of carrying out the technique at room temperature, without any preheating necessary before rolling. Compared to other SPD techniques (ECAP, HPT, ARB, AR, TE, and GP), the FL-ARB technique can produce the largest equivalent strain in the workpiece with the same number of passes.

Further investigations are being carried out with different materials such as other $\mathrm{Al}$ grades, Ti, etc. to further assess the capability of the FL-ARB technique.

\section{ACKNOWLEDGMENTS}




\section{ACCEPTED MANUSCRIPT}

The lead author gratefully acknowledges the financial support from the Vice-Chancellor's Fellowship Grant and URC small grant at the University of Wollongong, and from the National Natural Science Foundation of China through Grant 51105071. The lead author also thanks Dr. Xiong LIU and PhD student Syamsul HADI for their help with the experiments, and Dr. Ajit GODBOLE for discussing the paper.

\section{REFERENCES}

1. Saito, Y.; Utsunomiya, H.; Tsuji, N.; Sakai, T. Novel ultra-high straining presses for bulk materials - development of the accumulative roll-bonding (ARB) process. Acta Materialia 1999, 47, 579-583.

2. Hockauf, M.; Meyer, L. W. Work-hardening stages of AA1070 and AA6060 after severe plastic deformation. Journal of Materials Science 2010, 45, 4778-4789.

3. Luis, C.J.; Puertas, I.; Luri, R.; Leon, J.; Salcedo, D.; Perez, I. Development of nanostructured Armco-Fe by equal channel angular extrusion (ECAE). Materials and Manufacturing Processes 2012, 27, 1276-1284.

4. Ito, Y; Horita, Z. Microsturctural evolution in pure aluminum processed by high-pressure torsion. Materials Science and Engineering A 2009, 503, 32-36.

5. Zhang, J. W.; Gao, N.; Starink, M. J. Al-Mg-Cu based alloys and pure Al processed by high pressure torsion, the influence of alloying additions on strengthening. Materials

Science and Engineering A 2010, 527, 3472-3479. 


\section{ACCEPTED MANUSCRIPT}

6. Sajadi, A.; Ebrahimi, M.; Djavanroodi, F. Experimental and numerical investigation of Al properties fabricated by CGP process. Materials Science and Engineering A 2012, 552, 997-1003.

7. Morattab, S.; Ranjbar, K.; Reihanian, M. Investigation on the mechanical properties and microstructure of commercially pure $\mathrm{Al}$ fabricated by semi-constrained groove pressing. Materials Science and Engineering A 2011, 528, 6912-6918.

8. Krishnaiah, A.; Chakkingal, U.; Venugopal, P. Production of ultrafine grain sires in aluminium sheets by severe plastic deformation using the technique of groove pressing. Scripta Materialia 2005, 52, 1229-1233.

9. Orlov, D.; Beygelzimer, Y.; Synkov, S.; Varyukhin, V.; Tsuji, N.; Horita, Z. Microstructure Evolution in pure Al processed with twist extrusion, Materials Transactions 2009, 50, 96-100.

10. Yu, H.L.; Lu, C.; Tieu, K.; Liu, X.H.; Sun, Y.; Yu, Q.B.; Kong, C. Asymmetric cryorolling for fabrication of nanostructural aluminum sheets. Scientific Reports 2012, 2, 772.

11. Zuo, F.Q.; Jiang, J.H.; Shan, A.D.; Fang, J.M.; Zhang, X.Y. Shear deformation and grain refinement in pure $\mathrm{Al}$ by asymmetric rolling. Transactions of Nonferrous Metals Society of China 2008, 18, 774-777.

12. Saito, Y.; Tsuji, N.; Utsunomiya, H.; Sakai, T.; Hong, R.G. Ultra-fine grained bulk aluminum produced by accumulative roll-bonding (ARB) process. Scripta Materialia 1998, 39, 1221-1227. 


\section{ACCEPTED MANUSCRIPT}

13. Pirgazi, H.; Akbarzadeh, A.; Petrov, R.; Kestens, L. Microstructure evolution and mechanical properties of AA1100 aluminum sheet processed by accumulative roll bonding. Materials Science and Engineering A 2008, 497, 132-138.

14. Raei, M.; Toroghinejad, M.R.; Jamaati, R. Nano/ultrafine structured AA1100 by ARB process. Materials and Manufacturing Processes 2011, 26, 1352-1356.

15. Faraji, G.; Mashhadi, M.M.; Kim, H.S. Microstructural evolution of UFG magnesium alloy produced by accumulative back extrusion (ABE). Materials and Mnaufacturing Processes 2012, 27: 267-272.

16. Li, H.; Nagai, K.; Yin, F.X. Progress in cold roll bonding of metals. Sciences and Technology of Advanced Materials 2008, 9, 023001.

17. Kavarana, F.H.; Ravichandran, K.S.; Sahay S.S. Nanoscale steel-brass multilayer laminates made by cold rolling: microstructure and tensile properties. Scripta Materials 2000, 42, 947-954.

18. Kubota, M. Properties of nano-structured pure Al produced by mechanical grinding and spark plasma sintering. Journal of Alloys and Compound 2007, 434-435, 294-297. 19. Edalati, K.; Horita, Z. Significance of homologous temperature in softening behavior and grain size of pure metals processed by high-pressure torsion. Materials Science and Engineering A 2011, 528, 7514-7523.

20. Khamsuk, S.; Park, N.; Adachi, H.; Terada, D.; Tsuji, N. Evolution of ultrafine microstructures in commercial purity aluminum heavily deformed by torsion. Journal of Materials Science 2012, 47, 7841-7847. 


\section{ACCEPTED MANUSCRIPT}

21. Kamachi, M.; Furukawa, M.; Horita, Z.; Langdon, T. G. A model investigation of the shearing characteristics in equal-channel angular pressing. Materials Science and Engineering A 2003, 347, 223-230.

22. Yu, H.L.; Lu, C.; Tieu, A.K.; Godbole A.; Su, L.H.; Sun, Y.; Liu, M.; Tang, D.L.;

Kong, C. Fabrication of ultra-thin nanostructured bimetallic foils by accumulative roll bonding and asymmetric rolling. Scientific Reports 2013, 3, 2373.

23. Yu, H.L.; Liu, X.H.; Li, X.W.; Godbole, A. Crack healing in a low-carbon steel under hot plastic deformation. Metallurgical and Materials Transactions A 2013, DOI: 10.1007/s11661-013-2049-4.

24. Madaah-Hosseini, H.R.; Kokabi, A.H. Cold roll bonding of 5754-aluminum strips. Materials Science and Engineering A 2002, 335, 186-190.

25. Govindaraj, N.V.; Lauvdal, S.; Holmedal, B. Tensile bond strength of cold roll bonded aluminium sheets. Journal of Materials Processing Technology 2013, 213, 955-960. 


\section{ACCEPTED MANUSCRIPT}

Table 1.-Chemical composition of Al 1235

\begin{tabular}{|l|l|l|l|l|l|l|l|l|}
\hline Component & $\mathrm{Si}+\mathrm{Fe}$ & $\mathrm{Cu}$ & $\mathrm{Mn}$ & $\mathrm{Mg}$ & $\mathrm{Zn}$ & $\mathrm{Ti}$ & $\mathrm{V}$ & $\mathrm{Al}$ \\
\hline wt \% & $\leq 0.65$ & $\leq 0.05$ & $\leq 0.05$ & $\leq 0.05$ & $\leq 0.10$ & $\leq 0.06$ & $\leq 0.05$ & Balance \\
\hline
\end{tabular}




\section{ACCEPTED MANUSCRIPT}

Table 2.-Equivalent strain per pass after various SPD treatments.

\begin{tabular}{|c|c|c|}
\hline SPD Techniques & Equivalent strain equation & Equivalent strain per pass \\
\hline GP [6] & $\varepsilon_{e}=\frac{N \gamma_{x y}}{\sqrt{3}}$ & 0.56 \\
\hline $\mathrm{ARB}$ & $\varepsilon_{e}=\frac{2 N}{\sqrt{3}} \ln \left(h_{0} / h_{1}\right)$ & 0.8 \\
\hline HPT [20] & $\varepsilon_{e}=\frac{2 N \pi}{\sqrt{3}} \frac{r}{L}$ & 0.8 \\
\hline ECAP [21] & $\varepsilon_{e}=\frac{N}{\sqrt{3}}\left[2 \cot \left(\frac{\Phi}{2}+\frac{\Psi}{2}\right)+\Psi \operatorname{cosec}\left(\frac{\Phi}{2}+\frac{\Psi}{2}\right)\right]$ & 1.0 \\
\hline TE [9] & $\begin{array}{l}\varepsilon_{\max }=\frac{2}{\sqrt{3}} \tan \beta \\
\varepsilon_{\min }=0.4+0.1 \tan \beta\end{array}$ & 1.2 \\
\hline FL-ARB & $\varepsilon_{e}=\frac{2 N}{\sqrt{3}} \ln \left(h_{0} / h_{1}\right)$ & 1.6 \\
\hline AR & $\varepsilon_{e}=\frac{2}{\sqrt{3}}\left\{1+\left[\frac{(1-r)^{2}}{r(2-r)} \tan \theta\right]^{2}\right\}^{1 / 2} \ln \frac{1}{1-r}$ & Uncertain \\
\hline
\end{tabular}




\section{ACCEPTED MANUSCRIPT}

Figure 1.-Bond strength vs. reduction in deformation during cold rolling.

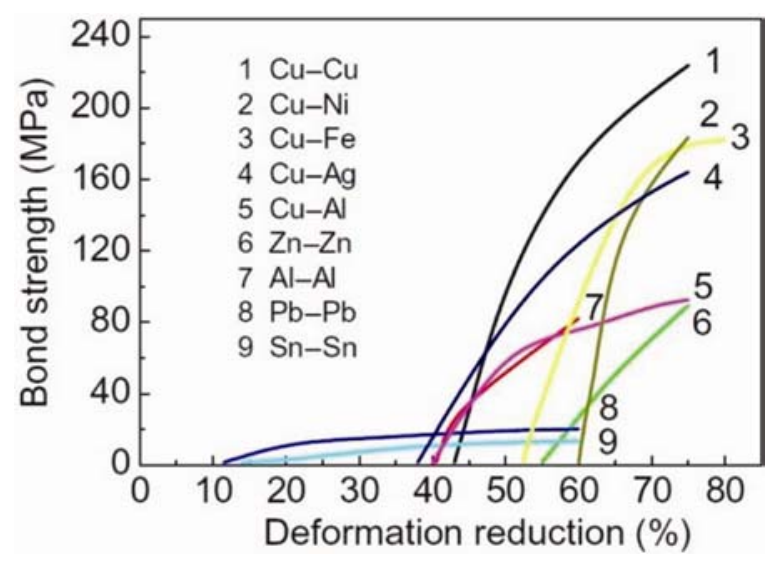




\section{ACCEPTED MANUSCRIPT}

Figure 2.-Four-layer accumulative roll bonding technique.

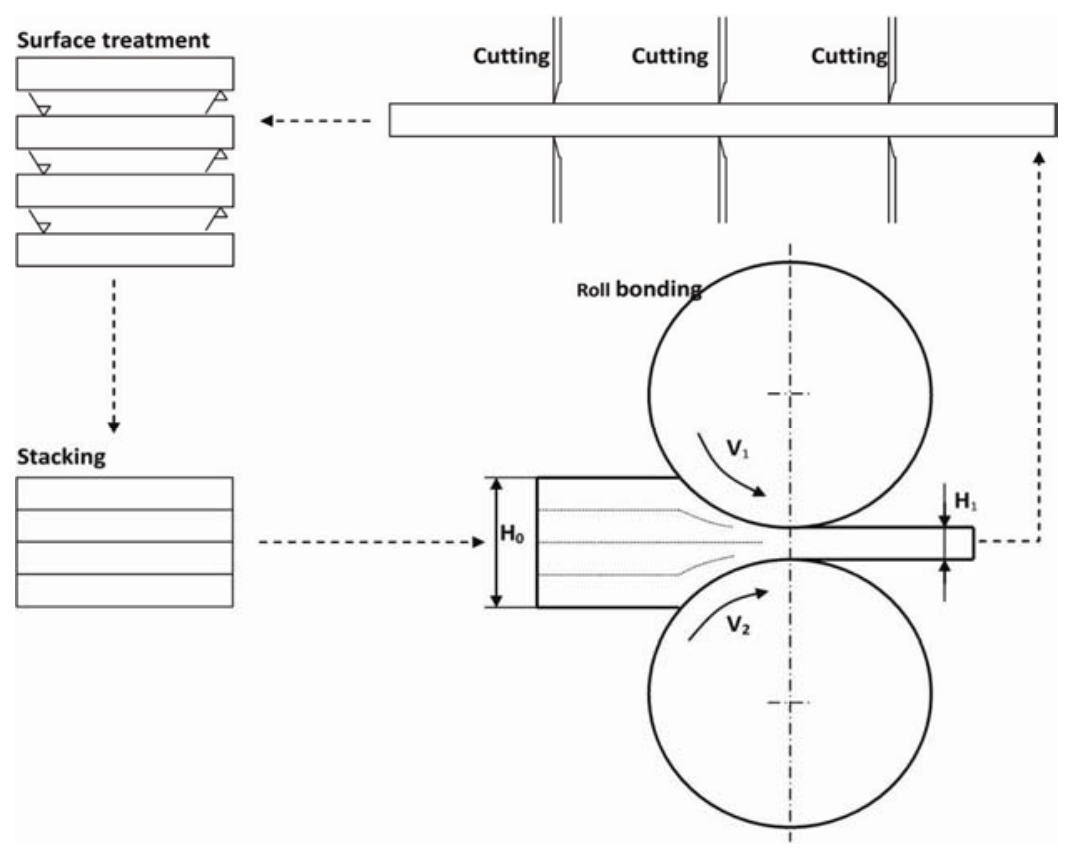




\section{ACCEPTED MANUSCRIPT}

Figure 3.-TEM images of samples after (a) first, (b) second and (c) third FL-ARB pass and (d) the Vickers micro-hardness after each pass.
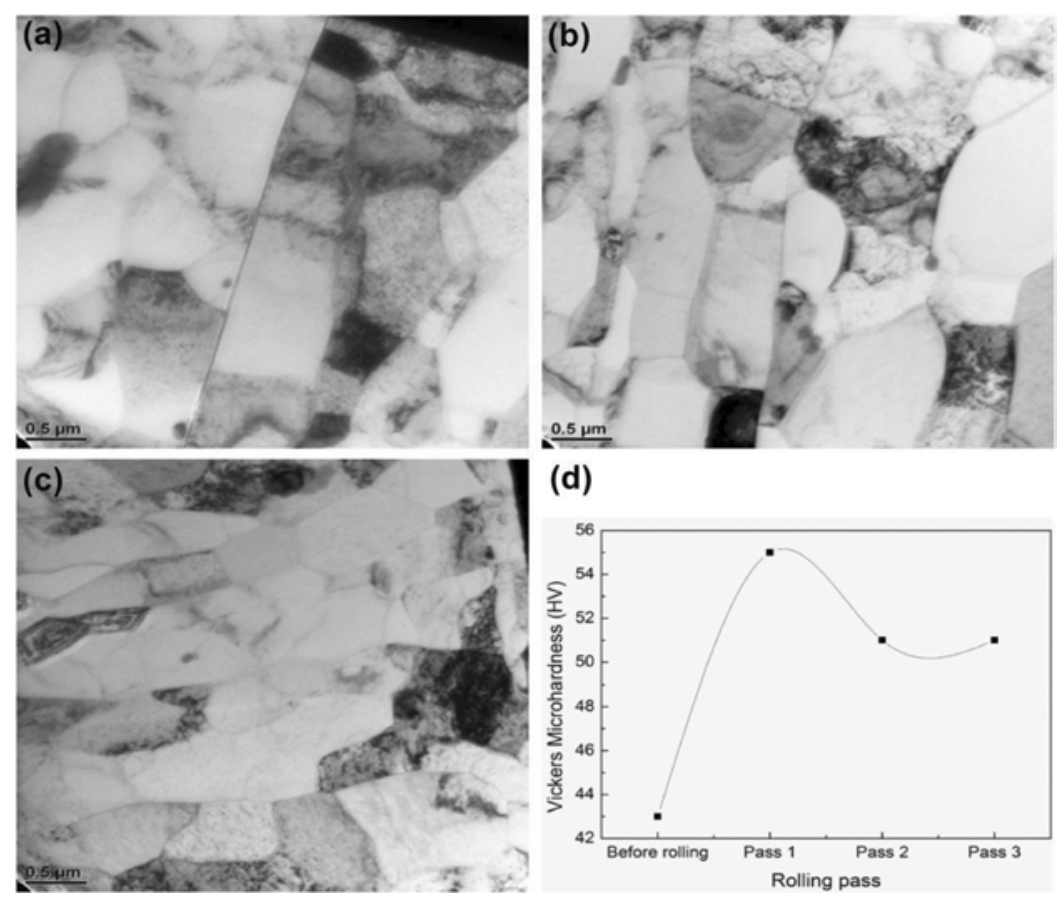

(d)

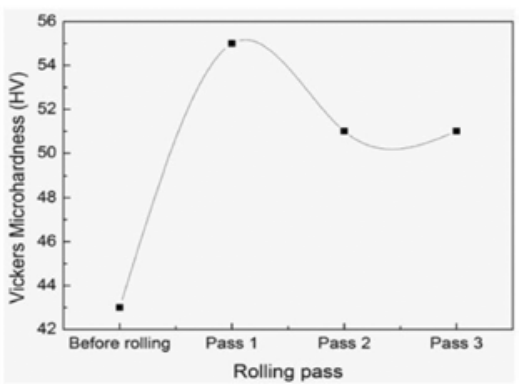




\section{ACCEPTED MANUSCRIPT}

Figure 4.-Grain size of pure aluminum after various SPD techniques.

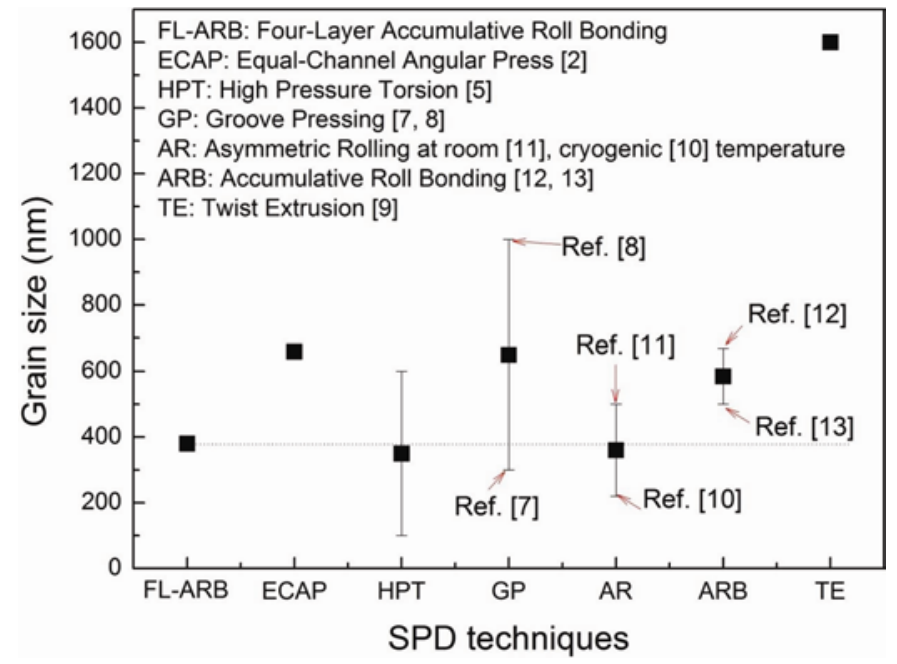




\section{ACCEPTED MANUSCRIPT}

Figure 5.-Interface of samples by traditional ARB: (a) cold rolling; (b) warm rolling.
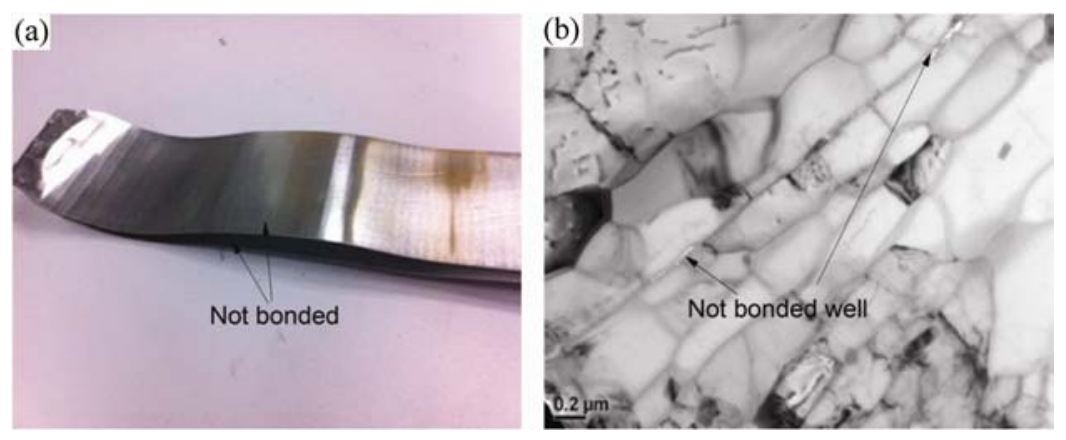


\section{ACCEPTED MANUSCRIPT}

Figure 6. -Reduction ratio vs number of stacked sheets

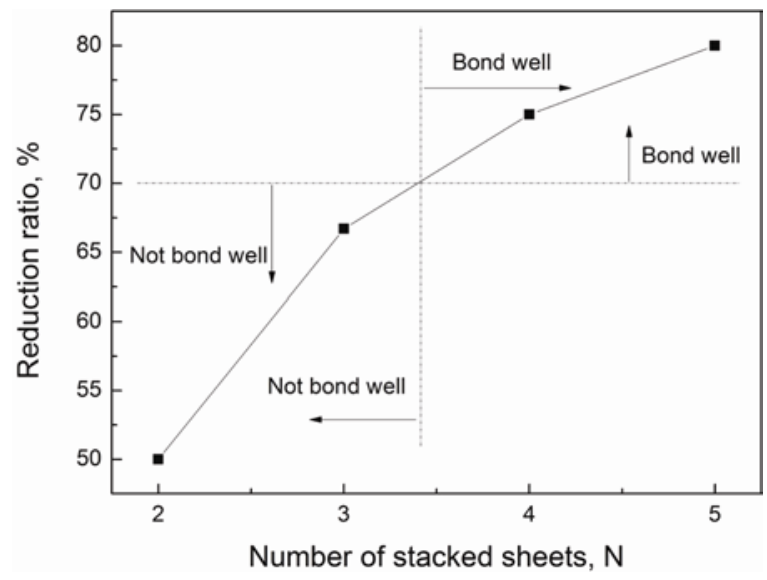

